\title{
Effects of Outdoor Thermal Environment upon the Human Responses
}

\section{Yoshihito Kurazumi ${ }^{1}$, Emi Kondo², Kenta Fukagawa ${ }^{3}$, Yoshiaki Yamato4, Kunihito Tobita ${ }^{5}$, Tadahiro Tsuchikawa ${ }^{6}$}

\author{
${ }^{1}$ School of Life Studies, Sugiyama Jogakuen University, Nagoya, Japan \\ ${ }^{2}$ Department of Architecture, Ariake National College of Technology, Omuta, Japan \\ ${ }^{3}$ Department of Architecture, Kyushu Sangyo University, Fukuoka, Japan \\ ${ }^{4}$ Department of Architecture and Structural Engineering, Kure National College of Technology, Kure, Japan \\ ${ }^{5}$ School of Humanities and Social Sciences, Osaka Prefecture University, Sakai, Japan \\ ${ }^{6}$ School of Human Science \& Environment, University of Hyogo, Himeji, Japan \\ Email:kurazumi@sugiyama-u.ac.jp
}

How to cite this paper: Kurazumi, Y. Kondo, E., Fukagawa, K., Yamato, Y., Tobita, K. and Tsuchikawa, T. (2019) Effects of Outdoor Thermal Environment upon the Human Responses. Engineering, 11, 475-503. https://doi.org/10.4236/eng.2019.118034

Received: July 11, 2019

Accepted: August 20, 2019

Published: August 23, 2019

Copyright (c) 2019 by author(s) and Scientific Research Publishing Inc. This work is licensed under the Creative Commons Attribution International License (CC BY 4.0)

http://creativecommons.org/licenses/by/4.0/

(c) (i) Open Access

\begin{abstract}
In a summer outdoor space, the influence of short-wave length solar radiation on the human body is strongly apparent, heat is retained in the body, and the risk of heat disorders such as heat stroke increases. To avoid this, it is essential to seek shade to avoid the influence of short-wave length solar radiation. In addition, natural ground surfaces such as green spaces and water surfaces are useful in reducing the air temperature. It is indispensable to consider climate mitigation effect of outdoor space. The purpose of this study is to clarify the influence of the thermal environment of an outdoor space on the human body in rural and suburban regions where paddy fields remain. Subject experiments were conducted to examine the relationship between the thermal environment evaluation index enhanced conduction-corrected modified effective temperature (ETFe) in an outdoor space and the physiological and psychological responses of the human body. Experiment sites were selected with consideration for the natural ground surface such as bare ground where the surface is gravel or soil; paved ground such as concrete, asphalt or blocks; green areas covered in plants; and water surfaces, as well as the sky factor due to buildings or trees etc. and the proportion of the solid angle of components of greenery and water etc. comprising the solid angle of the total celestial sphere. A ground surface feature with a high heat capacity may promote sensation of hot and deteriorate the thermal sensation. A landscape of thick vegetation with a high green factor may have a strong feeling of confinement, which can make it somewhat hot and somewhat uncomfortable thermal environment due to the sense of stagnation. Compared with the ur-
\end{abstract}


ban environment, it is conceivable that the difference in the perceptual environment, whereby it is subconsciously assumed to be a comfortable thermal environment, had an effect in the rural and suburban regional environment, resulting in an ETFe lower than the upper limit of comfort in a summer urban environment.

\section{Keywords}

ETFe, Mean Skin Temperature, Outdoor Environment, Rural Area, Thermal Comfort, Thermal Sensation, Urban Area

\section{Introduction}

In an outdoor space, in addition to physical and biological environmental factors, psychological environmental stimuli are important in determining thermal comfort [1]-[8]. Adaption to the thermal environment according to cultural background, experience of being in hot/cold thermal environments and the like, sense of expectation of the thermal environment, behavioral thermal regulation and the effect of the thermal environment history such as the time spent exposed to it are apparent in reported comfort. In these studies, the association between the outdoor thermal environment evaluation index and the thermal sensation of the human body is not made clear, and remains within the category of qualitative discussion.

Kurazumi et al. [9] [10] [11] quantitatively evaluate the influence on the human body in the outdoor thermal environment using enhanced conduction-corrected modified effective temperature (ETFe) [12] as an evaluation axis. In this series of studies, the sense of expectation with regards to comfort in outdoor spaces is low and the subjects are not judged to be comfortable thermal environments, so it is considered that even thermal environmental conditions with a high ETFe and thermal environmental conditions with high mean skin temperature can be tolerated as well as thermal environment conditions with a low ETFe and thermal environmental conditions with low mean skin temperature. The outdoor thermal environment being in a harsh condition is shown quantitatively by the outdoor thermal environment evaluation index ETFe.

Givoni et al. [13], Oliveira and Andrade [14], Eliasson et al. [15], Nikolopoulou and Steemers [5], Nikolopoulou and Lykoudis [7] and Ishii et al. [16] show the relationship between the physical environmental factors of the outdoor space and the thermal sensation of the human body, and clarify that the outdoor environmental factors that influence the thermal sensation of the human body are air temperature, wind speed and short-wave length solar radiation. However, these studies do not measure the physiological parameters of the human body necessary to calculate the heat balance of the human body. Kurazumi et al. [9] [17] measure the physiological parameters of the human body necessary to calculate the heat balance of the human body, and demonstrate the effect of outdoor 
thermal environment factors on the thermal sensation of the human body. Kurazumi et al. [9] clarify that the variable factors by which summer outdoor environmental factors influence the thermal sensation of the human body are heat conduction, humidity and short-wave length solar radiation. In addition, it clarifies that the variable factors that affect the thermal comfort of the human body are air current, heat conduction and humidity. Also, Kurazumi et al. [17] clarify that the variable factors by which winter outdoor environmental factors influence the thermal sensation of the human body are air temperature, long-wave length thermal radiation and short-wave length solar radiation. In addition, it clarifies that the variable factors that influence the thermal comfort of the human body are air temperature, humidity, long-wave length thermal radiation, short-wave length solar radiation and heat conduction. These studies quantitatively show the influence of outdoor thermal environmental factors on the thermal sensation of the human body.

Kurazumi et al. [18] [19] [20] demonstrate the influence of an outdoor thermal environment on the human body for the influence of a tropical climate with strong short-wave length solar radiation on the thermal sensation of the human body as the evaluation axis. It clarifies that in tropical areas where the effects of nighttime cooling cannot be expected, the effect of long-wave length thermal radiation is strong in the shade of objects made of materials with high heat capacity, and the effect of improving the thermal sensation of the human body through shade is low. These studies quantitatively show that when the outdoor thermal environment is harsh, it is essential to reduce the influence of long-wave length thermal radiation.

The influence of large-scale green space, rivers, etc. on the summer outdoor thermal environment is measured [21]-[26]. These studies quantitatively show the influence of outdoor thermal environmental factors on the thermal sensation of the human body. Meanwhile, the influence of park lakes, agricultural ponds, etc., on the summer outdoor thermal environment is measured [27] [28] [29]. The environment is influenced by the depth of water, the temperature of the surface of the water and the direction of the wind, but the trend is observed whereby the air temperature tends to be lower directly above the water surface and in the vicinity of the pond compared to the surrounding area. However, they consider air temperature reduction effect to be within a limited range. If the temperature of the water surface is higher than the air temperature, the air temperature on the downwind side of a pond across which wind blows tends to increase.

From the above, in a summer outdoor space, the influence of short-wave length solar radiation on the human body is strongly apparent, heat is retained in the body, and the risk of heat disorders such as heat stroke increases. To avoid this, it is essential to seek shade to avoid the influence of short-wave length solar radiation. However, under the cover of objects with large heat capacity, the effect of long-wave length thermal radiation becomes stronger and the environmental mitigation effect becomes lower. In addition, natural ground surfaces such as 
green spaces and water surfaces are useful in reducing the air temperature. However, concerning the effects of water surfaces, water depth, water flow and water temperature influence the temperature reduction effect.

Japan has a cereal-crop culinary culture and rice cultivation is actively carried out. There are many paddy fields in the suburbs, countryside, and mountainous areas. Even in urban areas, some paddy fields still remain. Although there are differences depending on the area, from May to September, paddy fields can be expected to be effective as green spaces and water surfaces. According to Nishida et al. [30] etc., the irrigation water temperature of the paddy field is influenced by the water temperature of the irrigation channel. In addition, the water temperature of the irrigation channel rises as it flows from upstream to downstream. Therefore, the irrigation water temperature is strongly affected by the water temperature of the water near the inlet. Meanwhile, the influence of the depth of irrigation is considered to be stronger near the paddy field drain. Regarding the relationship between the growth of rice and the water temperature of the paddy field, the influence of short-wave length solar radiation is stronger at the early stage of rice formation because the leaf area of the rice is small with respect to the change of the irrigation water temperature. At the stage of ripening of the head of the rice, regarding the change in the irrigation water temperature, the shielding rate of short-wave length solar radiation increases due to the increase in the leaf area due to the growth of the rice, and in addition to short-wave length solar radiation the influence of the air temperature increases. From the heading stage of rice onwards, the short-wave length solar radiation shielding rate further increases due to the inclination of the leaves of the rice, and changes in the irrigation water temperature are considered to be strongly influenced by air temperature.

Therefore, this study focused on the rural and suburban regions where paddy fields still remain, and aimed to clarify the relationship between outdoor thermal environment evaluation index ETFe [12] and the response of the human body with respect to thermal sensory perception. We decided to collect phenomena and information to quantitatively examine the outdoor thermal environment and effects on the human body.

\section{Experimental Plan}

\subsection{ETFe}

The thermal environment evaluation index for an outdoor space ETFe (enhanced conduction-corrected modified effective temperature) was developed by Kurazumi et al. [12]. Also, verification tests that clarify the relationship between ETFe and the physiological and psychological effect on the human body have been carried out, and its effectiveness as an outdoor environmental evaluation index has been clarified [9]. This sensational and physiological climatic environment index ETFe is considered to enable temperature-conversion of each effect of wind speed, long-wave length thermal radiation in the outdoor space, 
short-wave length radiation, surface temperature of the material in contact with the human body and humidity into individual meteorological elements.

The influence of these five environmental factors on the heat balance of the human body is considered to be expressible in newly defined thermal environment evaluation indices as follows: convective heat transfer area combined with the thermal velocity field $\mathrm{TVF}_{\mathrm{hta}}$ for wind speed; radiant heat transfer area combined with the effective radiation field concerning the long-wave length thermal radiation in outdoor space $\mathrm{ERF}_{\mathrm{htaL}}$ [12] for long-wave length thermal radiation; radiant heat transfer area combined with the effective radiation field concerning the short-wave length solar radiation in outdoor space $\mathrm{ERF}_{\text {htas }}$ [12] for short-wave length solar radiation; heat transfer area combined with the effective conduction field $\mathrm{ECF}_{\mathrm{hta}}[12]$ for surface temperature of the material in contact with the human body; and effective humidity field at enhanced conduction-corrected modified effective temperature $\mathrm{EHF}_{\mathrm{ETFe}}$ [12] for humidity. The addition of each temperature-converted factor is also considered to be possible and quantifying the composite effect on sensation in the outdoor space as well as the discrete effect of each meteorological element to possible on the same evaluation axis.

$$
\begin{gathered}
\mathrm{ETFe}=\mathrm{T}_{\mathrm{a}}+\mathrm{TVF}_{\mathrm{hta}} / \mathrm{h}_{\mathrm{fL}}+\mathrm{ERF}_{\text {htaL }} / \mathrm{h}_{\mathrm{fL}}+\mathrm{ECF}_{\text {hta }} / \mathrm{h}_{\mathrm{fL}} \\
+\mathrm{EHF}_{\mathrm{ETFe}} / \mathrm{h}_{\mathrm{fL}}+\mathrm{ERF}_{\text {htas }} / \mathrm{h}_{\mathrm{fL}} \\
\mathrm{TVF}_{\mathrm{hta}}=\left(\mathrm{h}_{\mathrm{o}} \mathrm{fclFclof}_{\text {conv }}-\mathrm{h}_{\mathrm{c}} \mathrm{fclFclf}_{\text {conv }}\right)\left(\mathrm{T}_{\mathrm{s}}-\mathrm{T}_{\mathrm{a}}\right) \\
\mathrm{ERF}_{\text {htaL }}=\mathrm{h}_{\mathrm{rL}} \mathrm{fclFclf}_{\text {rad }}\left(\mathrm{T}_{\mathrm{rL}}-\mathrm{T}_{\mathrm{a}}\right) \\
\mathrm{ECF}_{\mathrm{hta}}=\mathrm{h}_{\mathrm{d}} \operatorname{Fcldf}_{\text {cond }}\left(\mathrm{T}_{\mathrm{f}}-\mathrm{T}_{\mathrm{a}}\right) \\
\mathrm{EHF}_{\mathrm{ETFe}}=\mathrm{Lwh}_{\mathrm{c}} \text { fclFpcl}\left(\mathrm{p}_{\mathrm{a}}-0.5 \mathrm{p}_{\mathrm{ETFe}}^{*}\right) \\
\mathrm{ERF}_{\text {htas }}=\mathrm{R}_{\mathrm{S}} \\
\mathrm{h}_{\mathrm{fL}}=\mathrm{h}_{\mathrm{o}} \mathrm{fclFclof}_{\text {conv }}+\mathrm{h}_{\mathrm{rL}} \mathrm{fclFclf}_{\text {rad }}+\mathrm{h}_{\mathrm{d}} \text { Fcldf }_{\text {cond }}
\end{gathered}
$$

where:

ETFe: enhanced conduction-corrected modified effective temperature [K];

$\mathrm{T}_{\mathrm{a}}$ : air temperature $[\mathrm{K}]$;

$\mathrm{TVF}_{\mathrm{hta}}$ : convective heat transfer area combined with the thermal velocity field $\left[\mathrm{W} / \mathrm{m}^{2}\right]$;

$\mathrm{ERF}_{\mathrm{htaL}}$ : radiant heat transfer area combined with the effective radiation field concerning the long-wave length thermal radiation in outdoor space $\left[\mathrm{W} / \mathrm{m}^{2}\right]$;

$\mathrm{ERF}_{\text {htas: }}$ : radiant heat transfer area combined with the effective radiation field concerning the short-wave length solar radiation in outdoor space $\left[\mathrm{W} / \mathrm{m}^{2}\right]$;

$\mathrm{ECF}_{\mathrm{hta}}$ : heat transfer area combined with the effective conduction field $\left[\mathrm{W} / \mathrm{m}^{2}\right]$;

EHF $_{\mathrm{ETF}}$ : effective humidity field at enhanced conduction-corrected modified effective temperature $\left[\mathrm{W} / \mathrm{m}^{2}\right]$;

$\mathrm{h}_{\mathrm{rL}}$ : radiant heat transfer coefficient concerning the long-wave radiation in outdoor space $\left[\mathrm{W} / \mathrm{m}^{2} \mathrm{~K}\right]$; 
fcl: effective surface area of clothing [-];

$\mathrm{f}_{\text {conv: }}$ : convective heat transfer area factor $[-]$;

$\mathrm{f}_{\text {cond }}$ : conductive heat transfer area factor $[-]$;

$\mathrm{f}_{\mathrm{rad}}:$ radiant heat transfer area factor $[-]$;

Fcl: thermal efficiency factor of clothing in the exposed airflow area [-];

Fcld: thermal efficiency factor of clothing in the heat conduction area [-];

Fclo: thermal efficiency factor of clothing under the standard condition [-];

Fpcl: permeation efficiency factor of clothing [-];

$\mathrm{h}_{\mathrm{c}}$ : convective heat transfer coefficient $\left[\mathrm{W} / \mathrm{m}^{2} \mathrm{~K}\right]$;

$\mathrm{h}_{\mathrm{d}}$ : resultant heat conductance $\left[\mathrm{W} / \mathrm{m}^{2} \mathrm{~K}\right]$;

$\mathrm{h}_{\mathrm{fL}}$ : sensible heat transfer coefficient in outdoor space $\left[\mathrm{W} / \mathrm{m}^{2} \mathrm{~K}\right]$;

$h_{0}$ : convective heat transfer coefficient under the standard condition $\left[\mathrm{W} / \mathrm{m}^{2} \mathrm{~K}\right]$;

L: Lewis relation coefficient $[\mathrm{K} / \mathrm{kPa}]$;

$\mathrm{p}_{\mathrm{a}}$ : water vapor pressure at the outdoor air temperature $[\mathrm{kPa}]$;

$\mathrm{p}_{\mathrm{ETFe}}^{*}$ : saturated water vapor pressure at enhanced conduction-corrected modified effective temperature $[\mathrm{kPa}]$;

$\mathrm{R}_{\mathrm{s}}$ : short-wave length solar radiation heat gain of human body $\left[\mathrm{W} / \mathrm{m}^{2}\right]$;

$\mathrm{T}_{s}$ : convection-corrected mean skin temperature $[\mathrm{K}]$;

$\mathrm{T}_{\mathrm{f}}$ : surface temperature of the contacted material $[\mathrm{K}]$;

$\mathrm{T}_{\mathrm{rL}}$ : mean radiant temperature concerning long-wave length thermal radiation in outdoor space $[\mathrm{K}]$;

w: skin wettedness $[-]$.

\subsection{Experimental Procedure}

In order to maintain consistency in the experimental data collection and measurement method of the outdoor environment taking the thermal environment evaluation index for an outdoor space ETFe [12] as an evaluation axis, the experimental method and test items of this study are the same as described in Kurazumi et al. [9] [10] [11] [17] [18] [19] [20].

Experiments were conducted in late July 2016 and from late August 2015 to the beginning of September, corresponding to the ripening period of rice in paddy fields. The observation points were drawn at random and the route to the points was undecided. With consideration for the burden on subjects, the experiment was concluded at a point two hours after commencement of the mobile observations on foot. Morning measurements were carried out in a period from around 10:00 to 13:00 and afternoon measurements were carried out in a period from around 13:00 to $16: 00$.

In indoor spaces such as laboratory experiments, it is exceedingly rare to test the subject in extremely hot or cold thermal environments. In general experiments that include a transition period or a heterogeneous thermal environment, the exposure experiment time period for the heat balance between the human body and the environment to become almost a steady state is the subject of the 
investigation. However, the thermal environment of summer outdoor spaces can be harsh to the extent that there are cases of death by heat stroke. Accordingly, one must avoid extended periods in outdoor spaces where one would be struck by direct high temperature solar radiation or strong low temperature winds. It is unavoidable that experiments on subjects in outdoor spaces treat a necessary transition period of a short time. Unlike an indoor space, it is difficult to consider spending extended periods in an outdoor thermal environment that can be considered uncomfortable, due to behavioral thermoregulation by means of environmental refuge behavior. With that, in consideration of the subjects' maintenance of a posture in a standing position and the response time of the Assman ventilated psychrometer, the actual measurement of the human body response and thermal environment in the mobile observations were performed ten minutes after having established the observation device. Naturally, it can be conjectured that the human body response will differ the longer the exposure time of the subjects, and the experimental period was determined with consideration for the safety of the subjects.

Subjects moved on foot to the observation point after having been seated and at rest for 60 minutes or longer in an air-conditioned indoor space inside a building. The experiment staff instructed the subjects that the psychological reporting was thermally specific thermal sensation and thermal comfort, and that they should report the average sensation during the exposure time. The movement speed of the subjects was made about $0.7 \mathrm{~m} / \mathrm{s}$.

After arriving at each measurement point, the subjects waited in a standing posture, during which time the experiment staff set up the measurement instruments for the thermal environment and preparations for measurement were concluded. Thereafter, the subjects were exposed to the thermal environment in a standing posture for ten minutes, as detailed above. The subjects were positioned around the thermal environment measurement instruments with the thermal environment measurement instruments in the center. As the subject of the research was the environment surrounding the observation stations, the point of gaze of the subjects was free and unfixed. After exposure, the subjects reported the average thermal sensation and the average thermal comfort for the whole body that they experienced for the time exposed at the observation point.

\subsection{Outline of the Observation Points}

Figure 1 shows the observation sites. Table 1 shows a summary of the observation points. Observation points were selected with consideration for the natural ground surface such as bare ground where the surface is gravel or soil; paved ground such as concrete, asphalt or blocks; green areas covered in plants; and water surfaces, as well as the condition of sky factor due to buildings or trees etc. and the proportion of the solid angle of components of greenery and water etc. comprising the solid angle of the total celestial sphere (hereafter, green factor). Nineteen observation points were chosen. 

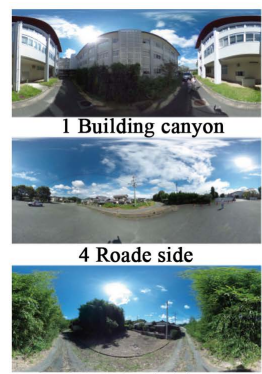

7 Farmland side
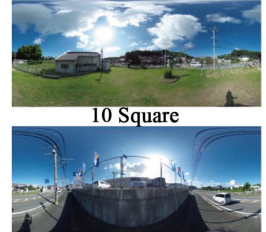

13 Roard side

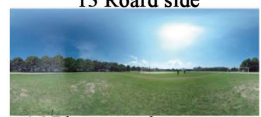

16 Playground green area

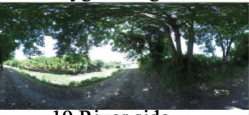

19 River side
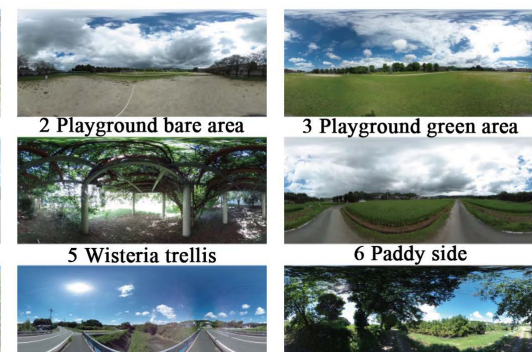

8 On the bridge
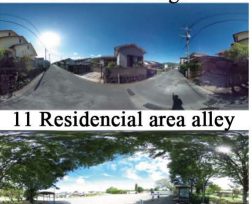

14 Bus stop

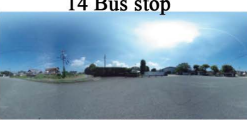

17 Roade side

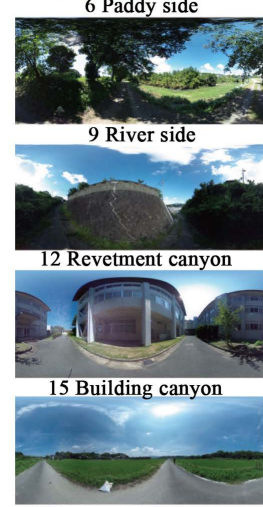

18 Paddy side

Figure 1. 360-degree panoramic photographs of observation site.

Table 1. Summary of observation points.

\begin{tabular}{|c|c|c|c|c|c|c|c|c|c|}
\hline Point & Survey site & Ground surface & $\begin{array}{l}\text { Skywards } \\
\text { surface }\end{array}$ & $\begin{array}{l}\text { Surrounds } \\
\text { North side }\end{array}$ & $\begin{array}{l}\text { Surrounds } \\
\text { East side }\end{array}$ & $\begin{array}{l}\text { Surrounds } \\
\text { South side }\end{array}$ & $\begin{array}{l}\text { Surrounds } \\
\text { West side }\end{array}$ & $\begin{array}{l}\text { Sky } \\
\text { factor }\end{array}$ & $\begin{array}{l}\text { Green } \\
\text { factor }\end{array}$ \\
\hline 1 & Building canyon & Asphalt \& Weed & Open & Building & Building & Building \& Tree & Open & 0.295 & 0.116 \\
\hline 2 & Playground bare area & Grass & Open & Open & Open & Open & Open & 0.920 & 0.046 \\
\hline 3 & Playground green area & Bare ground & Open & Open & Open & Open & Open & 0.951 & 0.481 \\
\hline 4 & Roadside & Asphalt & Open & Open & Open & Open & Open & 0.873 & 0.046 \\
\hline 5 & Wisteria trellis & Bare ground & Wisteria & Ivy & Ivy & Ivy & Ivy & 0.104 & 0.135 \\
\hline 6 & Paddy side & $\begin{array}{c}\text { Asphalt \& } \\
\text { Paddy field }\end{array}$ & Open & Open & Open & Open & Open & 0.938 & 0.132 \\
\hline 7 & Farmland side & Weed & Bamboo & Bamboo & Open & Open & Open & 0.506 & 0.338 \\
\hline 8 & On the bridge & Concrete \& River & Open & Open & Open & Open & Open & 0.913 & 0.035 \\
\hline 9 & River side & $\begin{array}{c}\text { Gravel \& } \\
\text { Weed \& River }\end{array}$ & Tree & Open & Open & Tree & Open & 0.352 & 0.411 \\
\hline 10 & Square & Grass \& Weed & Open & Open & Open & Building & Open & 0.870 & 0.532 \\
\hline 11 & Residencial area alley & Asphalt & Open & Building & Open & Open & Building & 0.690 & 0.019 \\
\hline 12 & Revetment canyon & Stone revetment & Open & Steep slope & Open & Stone revetment & Open & 0.620 & 0.157 \\
\hline 13 & Roadside & Asphalt & Open & Open & Open & Concrete revetment & Open & 0.718 & 0.000 \\
\hline 14 & Bus stop & Asphalt \& Weed & Tree & Open & Open & Tree & Open & 0.359 & 0.306 \\
\hline 15 & Building canyon & Asphalt \& Weed & Open & Building & Building & Building \& Tree & Open & 0.287 & 0.051 \\
\hline 16 & Playground green area & Grass & Open & Open & Open & Open & Open & 0.852 & 0.534 \\
\hline 17 & Roadside & Asphalt & Open & Open & Open & Open & Open & 0.864 & 0.091 \\
\hline 18 & Paddy side & $\begin{array}{c}\text { Asphalt \& } \\
\text { Paddy field }\end{array}$ & Open & Open & Open & Open & Open & 0.881 & 0.100 \\
\hline 19 & River side & $\begin{array}{c}\text { Gravel \& } \\
\text { Weed \& River }\end{array}$ & Tree & Open & Open & Tree & Open & 0.109 & 0.556 \\
\hline
\end{tabular}

Green factor is green covering factor. Green covering factor is defined as the ratio of green, water surface solid angles to celestial globe solid angle. 


\subsection{Subjects}

The subjects were 38 healthy young males and females. The age of the 21 young males was $22.0 \pm 2.1$, their height was $157.5 \pm 3.4 \mathrm{~cm}$, and their weight was 50.4 $\pm 5.6 \mathrm{~kg}$. The age of the 17 young females was $22.0 \pm 2.1$, their height was $157.5 \pm$ $3.4 \mathrm{~cm}$, and their weight was $50.4 \pm 5.6 \mathrm{~kg}$. With a BMI of $20.3 \pm 2.0$, they can be considered to be unremarkable test subjects.

In accordance with the Helsinki Declaration [31], the details of the experiment were fully explained to the subjects in advance and their consent to participate in the experiment was obtained.

To calculate the surface area of the human body, the body surface area calculation formula of Kurazumi et al. [32], the effectiveness of which as a calculation formula is verified [33], was used.

It is rare to perform a test subject experiment that measures physiological and psychological quantities as a response of the human body using a great number of test subjects. It is also difficult to perform an experiment that hypothesizes a statistical population. Therefore, this study is considered significant as being new data.

\subsection{Experimental Parameters}

Air temperature and humidity, wind speed, short-wave length solar radiation, long-wave length thermal radiation, and ground surface temperature of the central part of the experimental equipment were measured as thermal environment conditions. The air temperature and humidity were measured at a height of 90 $\mathrm{cm}$ above the ground by means of an Assmann ventilated psychrometer. The average wind speed was measured for 10 minutes at a height of $90 \mathrm{~cm}$ above the ground by a non-directional anemometer (Kanomax Japan, Inc.: 6533, measurement range $0.05-5.00 \mathrm{~m} / \mathrm{s})$. Concerning the short-wave length radiation in the regions from the visible to the near-and-mid-infrared and the terrestrial radiation in the far infrared region, radiation in downwards and upwards directions were measured at a height of $90 \mathrm{~cm}$ above the ground by long and short-wave length radiometer (EKO Instruments: MR-50, sensitivity $7 \mu \mathrm{V} / \mathrm{Wm}^{-2}$, short-wave length range 305 $2800 \mathrm{~nm}$, long-wave length range $5000-50,000 \mathrm{~nm}$ ). The ground surface temperature was measured by a radiation thermometer (KONICA MINOLTA: HT-10D, measurement wavelength $8-14 \mu \mathrm{m}$, measurement angle $1.4^{\circ}-2.0^{\circ}$, emissivity measurement range $0.10-1.00$ ).

The sky factor was measured by a photograph of the sky taken $90 \mathrm{~cm}$ above the ground at the observation point using a fisheye lens with an orthographical projection format (Yasuhara: Madoka $1807.3 \mathrm{~mm} \mathrm{f} / 4$ ) and a $35 \mathrm{~mm}$ digital SLR camera (Sony: $\alpha 7$ ). The proportion of the solid angle of components of greenery and water surfaces etc. comprising the solid angle of the total celestial sphere was measured by converting the orthographic projection map (Hugin by Pablo d'Angelo) in the zenith direction and nadir direction into a solid angle map. The albedo, sky temperature, and surface temperature were calculated from each di- 
rectional component of the short-wave length solar radiation and the long-wave length thermal radiation.

Skin temperature was measured as a physiological condition for the human body by a thermistor thermometer (NIKKISO-THERM N542R data logger, measurement range $-50^{\circ} \mathrm{C}-230^{\circ} \mathrm{C}$, resolution $0.01^{\circ} \mathrm{C}$ and a NIKKISO-THERM ITP8391 body surface probe). Medical surgical tape (NICHIBAN, NICHIBAN SURGICAL TAPE-21N) with excellent moisture permeability was used to attach the skin temperature sensor to the human body. The temperature of skin exposed to the airflow was measured at the seven positions of the head, trunk, arm, hand, thigh, lower leg and foot. The sole of the foot was measured for the temperature of the contact part skin. The subjects freely selected their clothing to be suitable to the weather on the measurement day. The clothing quantity of the subjects was found by the clo value given by layering the clothing reported by the subjects [34] [35].

As a psychological condition for the human body, the psychological response was measured after staying at the observation point for ten minutes by means of rating the whole-body thermal sensation (cold-hot) and the whole-body thermal comfort (uncomfortable-comfortable) on a linear scale [36] [37]. Linear rating scales are given for the hot (100) and cold (0), and comfortable (100) and uncomfortable (0) directions only. The arbitrary values of 0 and 100 are given for each endpoint, the reported values are read in, and the entire length is converted into a numerical value with the arbitrary scale of 100 for the linear rating scale.

Air temperature, humidity, wind speed, short-wave length solar radiation, long-wave length thermal radiation, and temperature of the ground surface in contact with the human body etc., which are direct environmental stimulus, have a large physiological or psychological influence on thermal sensory perception as explanatory variables for thermal sensory perception. Considering that the psychological reaction of the human body in an outdoor environment is likely to cause many disturbances and variations, the significance probability in this study is set at $10 \%$, as a criterion for comparison of explanatory variables for deriving results of regression analysis with higher usefulness from a practical perspective. JMP 14.3.0 (SAS Institute Japan) was used for statistical analysis.

\section{Results}

The total measurements for the total number of subjects at each observation point were 608. Table 2 shows the measurement results of the thermal environment factors at observation points during the measurement period. The short-wave length solar radiation downwards differed greatly in the sun and in the shade. Although it depends on the solar altitude and solar azimuth, and the influence of shielding on the south side, downward short-wave length solar radiation becomes stronger the higher the sky ratio of the observation site. Long-wave length thermal radiation is large at every observation site, and the influence of downward and upward thermal radiation is considered to be strong 
Table 2. Results of field survey.

\begin{tabular}{|c|c|c|c|c|c|c|c|c|c|c|}
\hline Date & Period & $\begin{array}{l}\text { Survey } \\
\text { site }\end{array}$ & $\begin{array}{l}\mathrm{Ta} \\
{\left[{ }^{\circ} \mathrm{C}\right]}\end{array}$ & $\begin{array}{c}\mathrm{Tf} \\
{\left[{ }^{\circ} \mathrm{C}\right]}\end{array}$ & $\begin{array}{l}\text { RH } \\
{[\%]}\end{array}$ & $\begin{array}{c}\mathrm{Va} \\
{[\mathrm{m} / \mathrm{s}]}\end{array}$ & $\begin{array}{l}\text { RSdwn } \\
{\left[\mathrm{W} / \mathrm{m}^{2}\right]}\end{array}$ & $\begin{array}{l}\text { RSup } \\
{\left[\mathrm{W} / \mathrm{m}^{2}\right]}\end{array}$ & $\begin{array}{l}\text { RLdwn } \\
{\left[\mathrm{W} / \mathrm{m}^{2}\right]}\end{array}$ & $\begin{array}{l}\text { RLup } \\
{\left[\mathrm{W} / \mathrm{m}^{2}\right]}\end{array}$ \\
\hline 28 Aug. 15 & $10: 20-10: 30$ & 1 & 26.2 & 32.5 & 82.5 & 0.55 & 174.0 & 17.3 & 445.4 & 480.2 \\
\hline 28 Aug. 15 & $10: 37-10: 47$ & 4 & 27.1 & 44.4 & 83.6 & 0.92 & 646.1 & 55.0 & 414.6 & 521.7 \\
\hline 28 Aug. 15 & $10: 55-11: 05$ & 2 & 26.8 & 37.1 & 80.6 & 1.26 & 873.4 & 284.3 & 417.2 & 512.1 \\
\hline 28 Aug. 15 & $11: 10-11: 20$ & 3 & 27.1 & 32.2 & 82.1 & 0.32 & 715.4 & 116.0 & 421.4 & 492.9 \\
\hline 28 Aug. 15 & $11: 30-11: 40$ & 5 & 27.9 & 25.5 & 76.5 & 0.72 & 18.8 & 0.6 & 463.4 & 459.0 \\
\hline 28 Aug. 15 & $13: 41-13: 51$ & 10 & 28.8 & 32.7 & 67.1 & 1.03 & 437.2 & 86.3 & 423.0 & 482.4 \\
\hline 28 Aug. 15 & $14: 09-14: 19$ & 11 & 29.2 & 44.4 & 61.2 & 0.80 & 435.9 & 46.5 & 437.1 & 540.5 \\
\hline 28 Aug. 15 & $14: 34-14: 44$ & 12 & 28.0 & 40.4 & 66.1 & 0.59 & 180.9 & 14.1 & 442.4 & 496.4 \\
\hline 28 Aug. 15 & $14: 56-15: 06$ & 13 & 30.0 & 40.0 & 59.6 & 0.87 & 183.3 & 16.9 & 436.8 & 518.8 \\
\hline 28 Aug. 15 & $15: 29-15: 39$ & 9 & 26.8 & 26.1 & 79.7 & 0.23 & 36.5 & 1.1 & 452.5 & 455.8 \\
\hline 9 Sep. 15 & $9: 41-9: 51$ & 1 & 25.0 & 30.5 & 79.4 & 0.62 & 249.7 & 26.7 & 430.7 & 473.1 \\
\hline 9 Sep. 15 & $9: 58-10: 08$ & 2 & 25.1 & 30.4 & 78.4 & 2.63 & 770.2 & 283.7 & 407.1 & 486.2 \\
\hline 9 Sep. 15 & $10: 18-10: 28$ & 4 & 26.4 & 43.4 & 75.8 & 1.63 & 862.9 & 77.0 & 420.0 & 536.5 \\
\hline 9 Sep. 15 & $10: 47-10: 57$ & 6 & 25.8 & 42.0 & 78.5 & 1.39 & 305.6 & 42.4 & 425.2 & 512.1 \\
\hline 9 Sep. 15 & $11: 05-11: 15$ & 7 & 27.0 & 40.2 & 75.0 & 1.46 & 420.7 & 51.4 & 434.4 & 478.8 \\
\hline 9 Sep. 15 & $11: 22-11: 32$ & 9 & 24.6 & 25.4 & 82.3 & 1.23 & 91.4 & 10.7 & 442.0 & 451.6 \\
\hline 9 Sep. 15 & $11: 41-11: 52$ & 8 & 26.0 & 44.9 & 78.6 & 1.80 & 988.3 & 96.7 & 401.5 & 534.4 \\
\hline 9 Sep. 15 & $12: 07-12: 17$ & 5 & 24.6 & 24.6 & 80.3 & 1.93 & 10.7 & 0.0 & 446.3 & 443.3 \\
\hline 9 Sep. 15 & $13: 45-13: 55$ & 13 & 25.6 & 39.7 & 76.6 & 2.48 & 757.2 & 47.2 & 412.2 & 506.8 \\
\hline 9 Sep. 15 & $14: 06-14: 16$ & 12 & 24.6 & 38.5 & 81.3 & 1.20 & 241.7 & 22.4 & 440.6 & 487.0 \\
\hline 9 Sep. 15 & $14: 38-14: 48$ & 10 & 24.8 & 25.9 & 79.4 & 2.21 & 395.7 & 77.5 & 421.7 & 468.7 \\
\hline 10 Sep. 15 & $9: 34-9: 44$ & 5 & 23.8 & 23.9 & 79.2 & 0.82 & 11.9 & 2.8 & 434.6 & 434.2 \\
\hline 10 Sep. 15 & $9: 52-10: 02$ & 1 & 24.3 & 29.7 & 77.8 & 0.51 & 149.3 & 36.2 & 423.3 & 470.2 \\
\hline 10 Sep. 15 & $10: 08-10: 18$ & 4 & 25.2 & 42.9 & 76.1 & 2.16 & 813.7 & 67.8 & 377.5 & 519.4 \\
\hline 10 Sep. 15 & $10: 26-10: 36$ & 3 & 25.0 & 30.0 & 78.4 & 1.59 & 709.8 & 123.4 & 381.1 & 478.0 \\
\hline 10 Sep. 15 & $10: 42-10: 52$ & 2 & 25.6 & 35.5 & 76.6 & 2.07 & 759.4 & 252.1 & 388.6 & 491.9 \\
\hline 10 Sep. 15 & $11: 36-11: 46$ & 14 & 23.2 & 24.4 & 85.3 & 1.89 & 98.8 & 1.6 & 422.9 & 442.5 \\
\hline 10 Sep. 15 & $13: 15-13: 25$ & 6 & 27.4 & 50.6 & 72.3 & 1.51 & 844.9 & 129.0 & 377.8 & 539.0 \\
\hline 10 Sep. 15 & $13: 34-13: 44$ & 7 & 27.8 & 45.8 & 69.8 & 1.53 & 852.0 & 132.0 & 426.5 & 541.5 \\
\hline 10 Sep. 15 & $13: 51-14: 01$ & 8 & 27.4 & 49.8 & 68.9 & 2.09 & 839.1 & 78.3 & 381.8 & 558.1 \\
\hline 10 Sep. 15 & $14: 16-14: 26$ & 14 & 26.2 & 25.2 & 71.2 & 2.79 & 58.9 & 2.6 & 423.7 & 451.3 \\
\hline 23 Jul. 16 & $9: 28-9: 38$ & 15 & 30.6 & 48.1 & 71.2 & 0.01 & 672.1 & 68.1 & 448.9 & 525.9 \\
\hline 23 Jul. 16 & $9: 51-10: 01$ & 16 & 30.9 & 41.8 & 71.3 & 0.01 & 785.3 & 155.7 & 409.0 & 512.8 \\
\hline 23 Jul. 16 & $10: 33-10: 43$ & 17 & 32.3 & 51.8 & 67.8 & 0.75 & 849.5 & 69.1 & 421.1 & 368.6 \\
\hline 23 Jul. 16 & $11: 04-11: 14$ & 18 & 32.2 & 56.6 & 65.8 & 0.48 & 908.2 & 124.0 & 422.9 & 574.7 \\
\hline 23 Jul. 16 & $11: 26-11: 36$ & 19 & 31.0 & 27.5 & 73.9 & 0.17 & 41.2 & 0.7 & 474.7 & 486.3 \\
\hline 23 Jul. 16 & $13: 30-13: 40$ & 19 & 32.4 & 29.7 & 69.4 & 0.01 & 44.7 & 6.6 & 474.8 & 485.7 \\
\hline 23 Jul. 16 & $13: 51-14: 01$ & 18 & 34.9 & 62.2 & 63.3 & 0.01 & 797.0 & 100.9 & 429.6 & 583.7 \\
\hline
\end{tabular}




\section{Continued}

\begin{tabular}{lccccccccccc}
\hline 23 Jul. 16 & $14: 43-14: 53$ & 17 & 34.8 & 63.9 & 57.2 & 1.62 & 765.8 & 69.7 & 435.3 & 612.9 \\
23 Jul. 16 & $14: 58-15: 08$ & 16 & 34.1 & 42.7 & 65.8 & 1.18 & 741.5 & 138.3 & 437.6 & 542.6 \\
23 Jul. 16 & $15: 27-15: 37$ & 15 & 35.4 & 58.2 & 57.3 & 0.64 & 466.4 & 43.8 & 476.9 & 589.3 \\
24 Jul. 16 & $9: 30-9: 40$ & 19 & 30.6 & 29.7 & 75.6 & 0.00 & 58.0 & 12.7 & 465.0 & 477.2 \\
24 Jul. 16 & $9: 52-10: 02$ & 18 & 32.3 & 47.2 & 73.2 & 0.00 & 801.9 & 113.5 & 427.4 & 507.7 \\
24 Jul. 16 & $10: 21-10: 31$ & 17 & 32.0 & 50.5 & 72.7 & 0.83 & 713.9 & 47.0 & 435.2 & 577.3 \\
24 Jul. 16 & $10: 43-10: 53$ & 16 & 32.2 & 45.1 & 75.8 & 1.21 & 881.3 & 171.3 & 427.5 & 540.6 \\
24 Jul. 16 & $11: 03-11: 13$ & 15 & 32.1 & 56.1 & 71.1 & 0.60 & 811.1 & 75.1 & 466.5 & 585.4 \\
24 Jul. 16 & $13: 08-13: 18$ & 15 & 33.7 & 57.8 & 65.3 & 0.54 & 645.3 & 62.8 & 477.9 & 587.4 \\
24 Jul. 16 & $13: 28-13: 38$ & 16 & 34.8 & 46.7 & 67.5 & 0.94 & 977.2 & 185.3 & 439.1 & 561.2 \\
24 Jul. 16 & $13: 51-14: 01$ & 17 & 35.3 & 61.8 & 59.1 & 1.58 & 970.4 & 85.0 & 440.6 & 630.9 \\
24 Jul. 16 & $14: 20-14: 30$ & 18 & 33.7 & 61.4 & 59.7 & 0.97 & 766.6 & 98.8 & 445.0 & 609.5 \\
\hline 24 Jul. 16 & $14: 40-14: 50$ & 19 & 33.1 & 31.0 & 70.4 & 0.12 & 55.6 & 1.7 & 486.4 & 494.0 \\
\hline
\end{tabular}

$\mathrm{Ta}$ is range of air temperature. Tf is range of ground surface temperature in the vicinity of the human body. RH is range of relative humidty. Va is range of air verocity. RSdwn is range of downward short wave solar radiation. RSup is range of upward short wave solar radiation. RLdwn is range of downward long wave radiation. RLup is range of upward long wave radiation.

even at observation sites where direct solar radiation is shielded. There is no remarkable difference between the average values of downward short-wave length solar radiation and downward long-wave length thermal radiation, and the intensity of long-wave length thermal radiation from the ground surface is shown. Therefore, it is considered that large environmental mitigation effect cannot be expected by simply seeking shade.

Kurazumi et al. [18] [19] [20] clarifies that when long-wave length thermal radiation is strong, the effect of shade in improving the thermal sensory perception of the human body is low. Compared with these studies, the outdoor thermal environment in the present study has an extremely high air temperature. Therefore, reducing the influence of long-wave length thermal radiation is also considered indispensable for mitigation of the thermal environment in the rural and suburban regions.

Instances where the temperature of the ground surface exceeds $60^{\circ} \mathrm{C}$ are also indicated at observation sites covered by asphalt pavement. Although the air temperature also has an effect, the influence of heating by downward short-wave length solar radiation and solar radiation absorptivity of the ground surface is observed. In addition, in a location where the ground surface is covered with plants or where there is a water surface, taking into account downward short-wave length solar radiation and the high temperature, long-wave length thermal radiation from the ground surface is relatively low.

Kurazumi et al. [9] [17] clarifies that heat conduction also influences the variable factors of the outdoor environment on the thermal sensory perception of the human body. Although the contact area between the human body in a standing posture and the ground surface is small, on ground surfaces with a low albedo, 
where short-wave length solar radiation is strong, and the reflected solar radiation is weak, heat gain of the human body by heat conduction is conjectured to have a strong effect on the contact skin temperature.

The surface temperature of the water surface is lower than the ground surface, which receives other short-wave length solar radiation, due to the influence of the heat capacity of paddy fields. According to Nishida et al. [30] etc., regarding the change in the irrigation water temperature at the stage of ripening of the head of the rice, the shielding rate of short-wave length solar radiation increases due to the increase in the leaf area due to the growth of the rice, and in addition to short-wave length solar radiation the influence of the air temperature increases. That is, it is conjectured that a natural ground surface such as the green areas and the water surfaces of paddy fields contribute to a long-wave length thermal radiation reduction effect.

The average value of the relative humidity is $72.8 \%$, the standard deviation is $7.3 \%$, and a noticeable difference in the measurement results is not shown. Accordingly, the influence that the difference in evaporation heat exchange has on sensational and physiological temperature is considered to be weak. However, taking into account the high-humidity thermal environment, this is considered to cause a humid heat.

Average wind speed was $1.1 \mathrm{~m} / \mathrm{s}$ and under $3 \mathrm{~m} / \mathrm{s}$ throughout all observations. The standard deviation is $0.7 \mathrm{~m} / \mathrm{s}$, and it may have an effect on thermal sensory perception as a variable factor of environmental change.

Oliveira and Andrade [14] states that wind speed has the strongest influence overall on thermal comfort. Kurazumi et al. [9] [17] considers the influence of the air current in both summer and winter seasons to be a factor that causes the outdoor thermal environment to affect the thermal sensation and thermal comfort of the human body. The human body may experience discomfort due to changing environmental factors, and so this experience can be thought to induce the condition of relative comfort. Accordingly, changes with an effect that mitigates thermal function are considered to be possible variables for discomfort with regards to other environmental factors also.

ETFe is an outdoor thermal environment evaluation index based on the heat balance of the human body. Accordingly, the calculation of the mean skin temperature used for the calculation of the heat balance of the human body was performed using a weighting coefficient that takes into account the convective heat transfer area [38]. Then, the mean skin temperature used for the physiological response of the human body was calculated using a weighting coefficient that takes into account the conductive heat transfer area [39]. The calculation formula of Kurazumi et al. [32], the validity of which as a calculation formula is verified [40], was used to calculate the surface area of the human body. The values of Kurazumi et al. [41] were used for the convective heat transfer area factor, radiant heat transfer area factor and conductive heat transfer area factor of the human body. The values of Miyamoto et al. [42] were used for the projected area factor of the human body. The values of Kuwabara et al. [43] were used for the 
radiant heat transfer coefficient and convective heat transfer coefficient of the human body. The Hendler et al. [44] value of 0.98 found from the reflectance of skin in electromagnetic waves of wavelength $3 \mu \mathrm{m}$ or more was used for the emissivity of the human body. The short-wave length solar radiation heat gain is affected by the solar radiation absorption factor. According to VDI3787-2 [45], the absorptivity of a clothed human body is 0.7. However, Watanabe et al. [46] shows the absorptivity of a human body wearing black clothing to be 0.76 and that of one wearing white clothing to be 0.38 . It also considers solar radiation absorptivity for other combinations of clothing or ordinary clothing to be within the range of the absorptivity of human body wearing black clothing or white clothing. In this study, the Hendler et al. [44] and Elam et al. [47] value of 0.70 found from the reflectance of skin in electromagnetic waves of wavelength $3 \mu \mathrm{m}$ or less was used for the solar radiation absorption factor of the human body. Concerning the skin wettedness, values calculated by the Kurazumi et al. [48] behavioral thermoregulation model were used because it was difficult to find the perspiration quantity. For the missing physiological quantities, values calculated by the behavioral thermoregulation model of Kurazumi et al. [48] were used. Moreover, the activity metabolic heat production was calculated using the ratio while seated position of Kurazumi et al. [49]. The outdoor thermal environment evaluation index ETFe theoretically proposed and verified by Kurazumi et al. [9] [12] was calculated from weather observation values, and the skin temperature and clo value of the human body.

\section{Discussion}

\subsection{Relationship between ETFe and Thermal Sensation}

Figure 2 shows the relationship between ETFe and thermal sensation. There is a spread in the psychological reaction of the human body in an outdoor environment due to many disturbances, but as the ETFe increases, the distribution of thermal sensation increases and the tendency for the sensation of hot to increase is shown. Significant spread in the psychological response of the human body is considered to occur due to the degree of freedom of mobilization in an outdoor space. The spread in thermal sensation becomes large in outdoor spaces due to the influence of environmental stimuli in addition to the psychological response to thermal action in the outdoor space. Although it can be thought of as a thermal adaptation, in this study experiments were carried out with the subjects instructed to give thermally unique evaluations of psychological reactions. However, in outdoor spaces that differ from laboratory tests, it is considered that the potential for environmental factors such as sight and hearing to impact on psychological response becomes high and this is expressed as a spread in evaluation values.

In addition, environmental stimuli in outdoor spaces are in a heterogeneous and unsteady state. Environmental stimuli are evaluated by the measurement points of measurement instruments. Although the physical reaction of the 


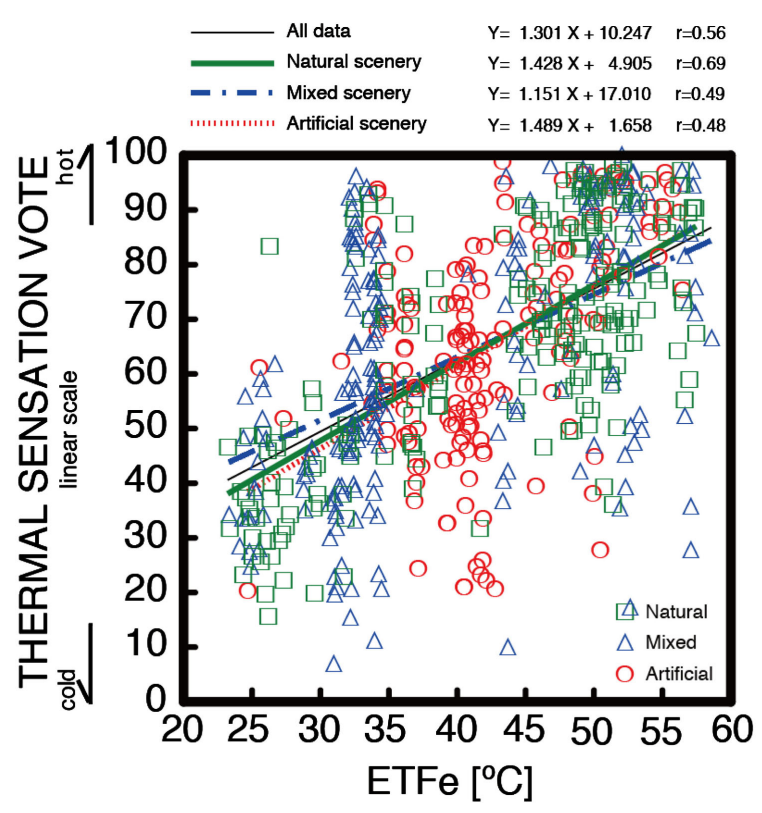

Figure 2. Relationship between ETFe and thermal sensation.

subjects is evaluated in the vicinity of the measurement instruments, it is exceedingly difficult to have multiple subjects exposed to identical environmental stimuli due to the effect of the influence of short-wave length solar radiation heat gain such as solar radiation shielding and the orientation of the human body with respect to the solar azimuth angle, and fluctuations in the air current, etc. The microclimate around the subjects may have affected the subjects' thermal sensation due to the difference in these environmental factors.

The outdoor thermal environmental factors of short-wave length solar radiation, long-wave length thermal radiation and the air current are nonuniform and non-targeted evaluation factors. These evaluation factors may contribute as a local effect on the human body, even if the heat balance in the whole human body is the same. Horikoshi et al. [50] clarifies that the psychological reactions of the human body in a heterogeneous/asymmetric thermal radiation environment have directionality which changes under the effect of local thermal radiation. Kurazumi et al. [51] [52] clarify that a parameter exists for the heterogeneous/asymmetric thermal environmental factors in the thermal environment evaluation factors that evaluate the effect on the human body in a heterogeneous/asymmetric thermal radiation environment. They show that there is a large spread in the response of the human body due to the effect of this parameter. That is, the spread in thermal sensory perception becomes large in outdoor spaces due to the influence of environmental stimuli in addition to the psychological response to thermal action in the outdoor space.

Kurazumi et al. [53] considers green factor to influence the thermal sensation of the human body. Taking less than $10 \%$ as artificial scenery, over $10 \%$ and less than $30 \%$ as mixed scenery, and $30 \%$ or more as natural scenery in order to grasp the relationship between the environment and the human body reaction 
makes it easy to explain the interaction. Accordingly, the relationship between ETFe and thermal sensation was examined by the green factor classification of Kurazumi et al. [53].

In a study to measure the psychological and physiological reactions in the outdoor environment, as a rule of thumb, good results have been obtained if there is about 0.4 coefficient of correlation [9] [10] [11] [17] [18] [19] [20] [53] [54]. In other words, the coefficient of determination is less than about 0.16. Therefore, it can be said that the measurement result in this research is appropriate.

Focusing on the regression line, the Thermal sensation tends to be higher as the ETFe becomes higher. Mixed scenery shows the tendency of the highest environmental mitigation effect. Looking at the difference in green factor at almost the same ETFe, mixed scenery shows a slightly different tendency from natural scenery and artificial scenery. When ETFe is low, the thermal sensation is high. Meanwhile, when ETFe is high, the thermal sensation is low.

Given the measurement results of thermal environment factors in Table 2, the mixed scenery observation point with high ETFe is 18 Paddy side. The condition of 18 is strong short-wave length solar radiation and long-wave length thermal radiation from the ground surface. Nishida et al. [30] considers the environmental mitigation effect of the surface of paddy field to be related to water depth and water flow. The measurement period is at the ripening stage of the head of the rice, so the short-wave length solar radiation shielding rate on the water surface is high, but due to the fact that there is no flow of water and the heat capacity is high, in the time period when there is a large cumulative amount of short-wave length solar radiation, long-wave length thermal radiation may increase.

As pointed out by Kurazumi et al. [53], it is conjectured that there is also a visual influence due to the natural surface coverage by vegetation, etc. However, natural scenery shows a thermal sensation slightly hotter than mixed scenery, giving a result whereby the effect of natural surface coverage by vegetation, etc. is not apparent. Fukagawa et al. [55] and Kurazumi et al. [56] [57] [58] consider a landscape of thick vegetation with a high green factor to have a strong feeling of confinement, which makes it somewhat hot and somewhat uncomfortable thermal environment due to the sense of stagnation. In this study too, it can be conjectured that thermal sensation increased due to the influence of the green factor enhancing this sense of confinement.

Similarly, given the measurement results of thermal environment factors in Table 2, the observation points of mixed scenery with low ETFe are 1 Building canyon, 5 Wisteria trellis, 6 Paddy side, 12 Revetment canyon. The weather was such that air temperatures at all observation points were relatively low. At 1 and 12, the human body did not receive direct solar radiation due to the solar azimuth. However, it is considered that the long-wave length thermal radiation from the concrete wall surface of a building with a high heat capacity subjected to short-wave length solar radiation and the stone wall of the revetment is 
strong. Both the concrete wall surface of the building and the stone wall of the revetment are close to the human body, so the angle factor with the human body is large and it is conjectured that the long-wave length thermal radiation heat gain increased. 6 is considered to have strong long-wave length thermal radiation from paddy fields in the time period when accumulated amount of short-wave length solar radiation becomes large, as a result of the high heat capacity of paddy fields. For 5, it is conjectured that the feeling of confinement caused by the surrounding wisteria promoting a sense of heat and increased the thermal sensation.

Therefore, it can be said that ground surface features with a high heat capacity and situations that evoke a feeling of confinement tend to increase the thermal sensation by promoting the sensation of hot.

An inspection of the parallelism of the regression lines gave $\mathrm{p}>0.10$ (RMSE $=$ $17.95, \mathrm{~F}=1.64, \mathrm{p}=0.19$ ), indicating no significant difference in the parallelism of the regression lines. An inspection of the homogeneity of regression gave $\mathrm{p}<$ 0.10 ( $\mathrm{RMSE}=21.64, \mathrm{~F}=2.52, \mathrm{p}=0.08$ ), indicating a significant difference in the homogeneity of the regression lines. As a result of multiple comparison by $\mathrm{Tu}$ key-Kramer, natural scenery and mixed scenery were $\mathrm{p}<0.10(\mathrm{p}=0.08)$, showing a significant difference. Therefore, it can be considered that the influence of the green factor was expressed in the thermal sensation.

Focusing on the regression line for all experimental results, the ETFe that gives a neither hot nor cold, thermally neutral thermal sensation of 50 is $30.6^{\circ} \mathrm{C}$. As identified by Humphreys [1], Brager and de Dear [2], and Kurazumi et al. [9] [10] [11], the sense of expectation that the thermal environment of an indoor space will be more comfortable than the air temperature of an outdoor space has an effect and it is considered possible that the neutral temperature for the indoor space will change. Unlike indoor spaces, the sense of expectation with regards to comfort in outdoor spaces is low to begin with and they are not judged to be comfortable thermal environments, so it is conceivable that this permissibility raised the neutral temperature, even for thermal environment conditions whereby ETFe is high. In this study on rural and suburban regions, the ETFe that gives a neutral thermal sensation of 50 is low in comparison to the subject experiments in the urban environment in Kurazumi et al. [9] [10] [11]. Compared with the urban environment, it is conceivable that the difference in the perceptual environment, whereby it is subconsciously assumed to be a comfortable thermal environment, had an effect in the rural and suburban regional environment.

\subsection{Relationship between ETFe and Thermal Comfort}

Figure 3 shows the relationship between ETFe and thermal comfort. There is a spread in the psychological reaction of the human body in an outdoor environment due to many disturbances, but as the ETFe increases, the distribution of thermal comfort decreases and the tendency for the sense of discomfort to increase is shown. In this research, the experiment was carried out having 


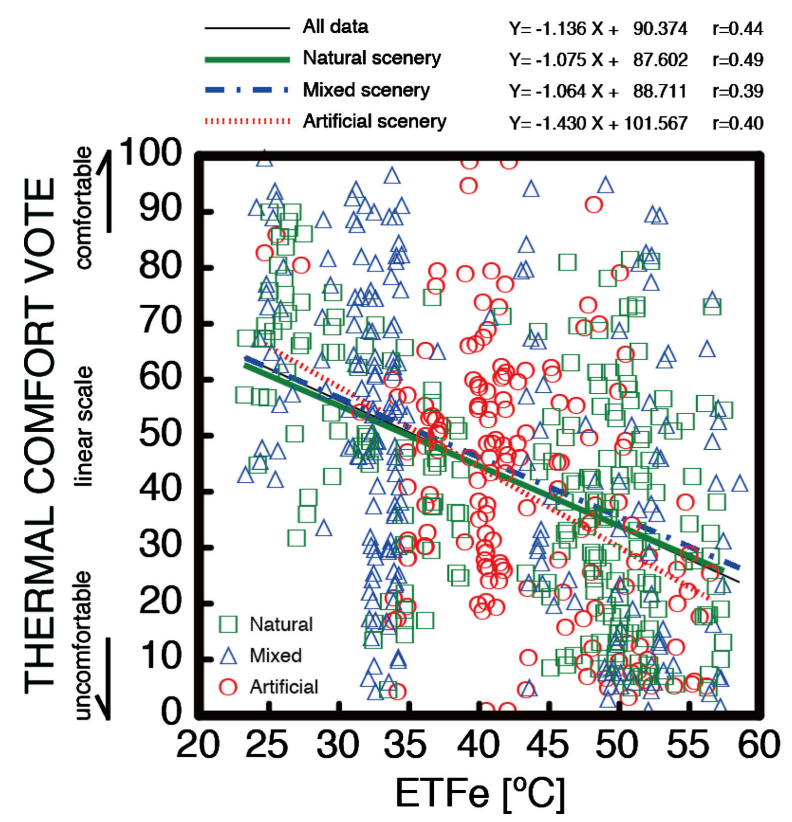

Figure 3. Relationship between ETFe and thermal comfort.

instructed the subjects instructed to give thermally unique evaluations of psychological reactions. However, in outdoor spaces that differ from laboratory tests, it is considered that the potential for environmental factors such as sight and hearing to impact on psychological response becomes high and this is expressed as a spread in evaluation values.

As stated in "Relationship between ETFe and thermal sensation", environmental stimuli in outdoor spaces are in a heterogeneous and unsteady state. The human body may experience discomfort due to changing environmental factors, and so this experience can be thought to induce the condition of relative comfort. Accordingly, changes with an effect that mitigates thermal function are considered to be variables for discomfort with regards to other environmental factors also [9] [10] [11].

Focusing on the regression line, the Thermal comfort tends to be lower as ETFe becomes higher. The tenancy was shown for artificial scenery to have the strongest level of discomfort. As identified by Kurazumi et al. [53], it is conjectured that there is also a visual influence due to the natural surface coverage by vegetation, etc.

An inspection of the parallelism of the regression lines gave $\mathrm{p}>0.10(\mathrm{RMSE}=$ $21.90, \mathrm{~F}=0.78, \mathrm{p}=0.46$ ), indicating no significant difference in the parallelism of the regression lines. An inspection of the homogeneity of regression gave $\mathrm{p}<$ $0.10(\mathrm{RMSE}=24.15, \mathrm{~F}=4.64, \mathrm{p}=0.01)$, indicating a significant difference in the homogeneity of the regression lines. As a result of multiple comparison by $\mathrm{Tu}-$ key-Kramer, mixed scenery and natural scenery, and mixed scenery and artificial scenery were both $p<0.10(p=0.02, p=0.03)$, showing a significant difference. Similar to the relationship between ETFe and thermal sensation, the comfort of mixed scenery is relatively high. Therefore, it can be considered that the influ- 
ence of green factor was expressed in the thermal comfort.

Focusing on the regression line for all experimental results, the ETFe that gives a neither comfortable nor uncomfortable thermal comfort of 50 is $35.5^{\circ} \mathrm{C}$. As already stated, the environmental stimuli in an outdoor space may evoke a human body response that differs to an indoor space. Also, unlike the relationship acquired for indoor spaces, the sense of expectation with regards to comfort in outdoor spaces is low to begin with and they are not judged to be comfortable thermal environments, so it is conceivable that even thermal environment conditions with high ETFe are permitted. In this study on rural and suburban regions, the ETFe that gives a neither comfortable nor uncomfortable thermal comfort of 50 is low in comparison to the subject experiments in the urban environment in Kurazumi et al. [9] [10] [11]. Compared with the urban environment, it is conceivable that the difference in the perceptual environment, whereby it is subconsciously assumed to be a comfortable thermal environment, had an effect in the rural and suburban regional environment.

\subsection{Relationship between Mean Skin Temperature and Thermal Sensation}

Figure 4 shows the relationship between mean skin temperature and thermal sensation. The trend is shown for the distribution of thermal sensation to increase as the mean skin temperature rises, and for sensation of hot to become strong. Significant spread in the psychological response of the human body in the outdoor space can be considered to occur due to the degree of freedom of mobilization in the experiment environment.

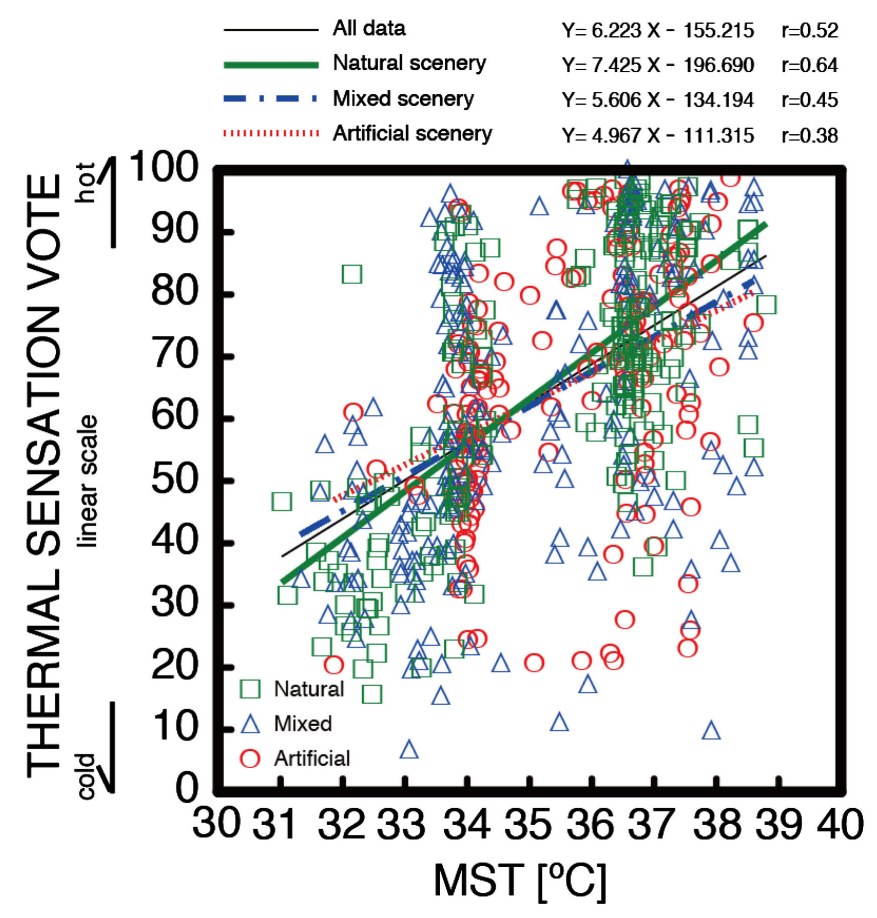

Figure 4. Relationship between mean skin temperature and thermal sensation. 


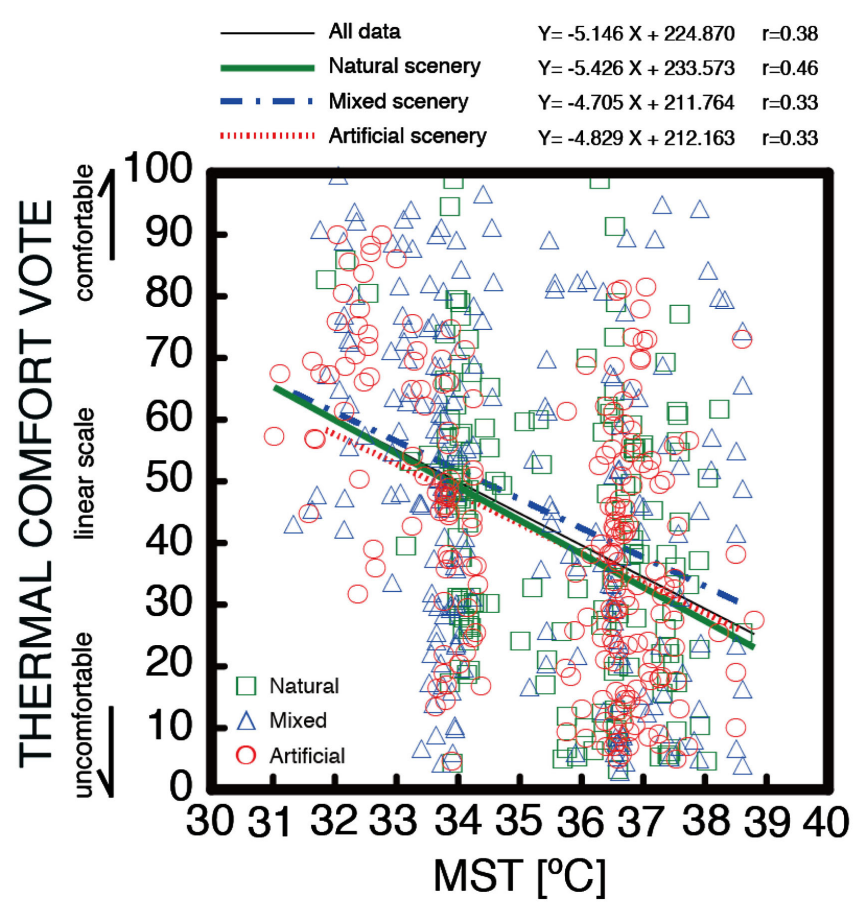

Figure 5. Relationship between mean skin temperature and thermal comfort.

As identified by Kurazumi et al. [59], when the measurement site of skin temperature is receiving strong short-wave length solar radiation and faces the azimuth angle of the short-wave length solar radiation, skin temperature exceeds $40^{\circ} \mathrm{C}$, and mean skin temperature is also significantly higher. In this study, it is considered that individual differences in mean skin temperature resulted from whether or not the skin temperature measurement site on the subject exposed to the thermal environment surrounding the environmental measuring instrument was directly facing the solar azimuth. It is considered essential to investigate the measurement site of the mean skin temperature in outdoor environments taking into account parts in the sun and in shade. From the measurement results of the above thermal environment factor, it is conceivable that the influence of short-wave length solar radiation and long-wave length thermal radiation is strong. Focusing on the regression line, the thermal sensation tends to be higher as the mean skin temperature becomes higher. The slope of natural scenery is the largest and the variation of thermal sensation with respect to the change of mean skin temperature is large. As stated in "Relationship between ETFe and thermal sensation", a situation that tends to generate a sense of confinement can be considered to increase thermal sensation by promoting the sensation of hot.

An inspection of the parallelism of the regression lines gave $\mathrm{p}<0.10($ RMSE $=$ $18.48, \mathrm{~F}=2.95, \mathrm{p}=0.05$ ), indicating a significant difference in the parallelism of the regression lines. An inspection of the homogeneity of regression gave $\mathrm{p}<$ $0.10(\mathrm{RMSE}=21.64, \mathrm{~F}=2.52, \mathrm{p}=0.08)$, indicating a significant difference in the homogeneity of the regression lines. As a result of multiple comparison by $\mathrm{Tu}-$ key-Kramer, mixed scenery and natural scenery were $\mathrm{p}<0.10(\mathrm{p}=0.08)$, show- 
ing a significant difference. Similar to the relationship between ETFe and thermal sensation, it can be considered that the influence of green factor was expressed in the thermal sensation.

Focusing on the regression line for all experimental results, the mean skin temperature that gives a neither hot nor cold, thermally neutral thermal sensation of 50 is $33.0^{\circ} \mathrm{C}$. In the subject experiments of Tsuchikawa et al. [60] on subjects in an indoor space, the mean skin temperature by which a standing human experiences a neither hot nor cold, thermally neutral sensation is reported to be $32.5^{\circ} \mathrm{C}$. In subject experiments of Kurazumi et al. [11] on subjects in an outdoor space, the mean skin temperature by which a standing human experiences a neither hot nor cold, thermally neutral sensation is reported to be $33.3^{\circ} \mathrm{C}$. The difference in mean skin temperature that gives a thermally neutral sensation between the urban environment and the rural and suburban environment is not large, but mean skin temperature is higher in the outdoor space than in the indoor space.

\subsection{Relationship between Mean Skin Temperature and Thermal Comfort}

Figure 5 shows the relationship between mean skin temperature and thermal comfort. The trend is shown for the distribution of thermal comfort to decrease as the mean skin temperature rises, and for discomfort to become strong. Significant spread in the psychological response of the human body in the outdoor space can be considered to occur due to the degree of freedom of mobilization in the experiment environment.

Focusing on the regression line, the thermal comfort tends to become lower as mean skin temperature increases. The slope of mixed scenery is the smallest and the variation of thermal comfort with respect to the change of mean skin temperature is large. The thermal comfort of the mixed scenery is the highest. As stated in "Relationship between ETFe and thermal comfort", it is conjectured that there is also a visual influence due to the natural surface coverage by vegetation, etc. [53]. However, the green factor classified as natural scenery is likely to produce a sense of confinement, conceivably promoting discomfort and lowering thermal comfort.

An inspection of the parallelism of the regression lines gave $\mathrm{p}>0.10(\mathrm{RMSE}=$ $22.45, \mathrm{~F}=0.22, \mathrm{p}=0.81$ ), indicating no significant difference in the parallelism of the regression lines. An inspection of the homogeneity of regression gave $\mathrm{p}<$ $0.10(\mathrm{RMSE}=24.15, \mathrm{~F}=4.64, \mathrm{p}=0.01)$, indicating a significant difference in the homogeneity of the regression lines. As a result of multiple comparison by $\mathrm{Tu}-$ key-Kramer, mixed scenery and natural scenery, and mixed scenery and artificial scenery were both $\mathrm{p}<0.10(\mathrm{p}=0.02, \mathrm{p}=0.03)$, showing a significant difference. Similar to the relationship between ETFe and thermal comfort, it can be considered that the influence of green factor was expressed in the thermal comfort.

Focusing on the regression line for all experimental results, the mean skin temperature that gives a neither comfortable nor uncomfortable thermal com- 
fort of 50 is $34.0^{\circ} \mathrm{C}$. In the subject experiments of Tsuchikawa et al. [60] on subjects in an indoor space, the mean skin temperature by which a standing human experiences a neither comfortable nor uncomfortable, thermally neutral sensation is reported to be $33.0^{\circ} \mathrm{C}$. As stated in "The relationship ETFe and thermal sensation", unlike indoor spaces, the sense of expectation for the degree of comfort in outdoor spaces is low to begin with and they are not judged to be comfortable thermal environments, so it is conceivable that even thermal environment conditions in which mean skin temperature becomes high were permitted. In addition, the effect of variations of the environmental factors is considered to contribute to mitigating the effect of discomfort.

\subsection{Relationship between Thermal Sensation and Thermal Comfort}

Figure 6 shows the relationship between thermal sensation and thermal comfort. The trend is shown for the distribution of thermal comfort to decrease as the thermal sensation increases, and for discomfort to become strong. Significant spread in the psychological response of the human body in the outdoor space can be considered to occur due to the degree of freedom of mobilization in the experiment environment.

Focusing on the regression line, the thermal comfort of the mixed scenery is the highest. An inspection of the parallelism of the regression lines gave $p>0.10$ ( $\mathrm{RMSE}=17.16, \mathrm{~F}=0.11, \mathrm{p}=0.90)$, indicating no significant difference in the parallelism of the regression lines. An inspection of the homogeneity of regression gave $\mathrm{p}<0.10$ (RMSE $=24.15, \mathrm{~F}=4.64, \mathrm{p}=0.01)$, indicating a significant

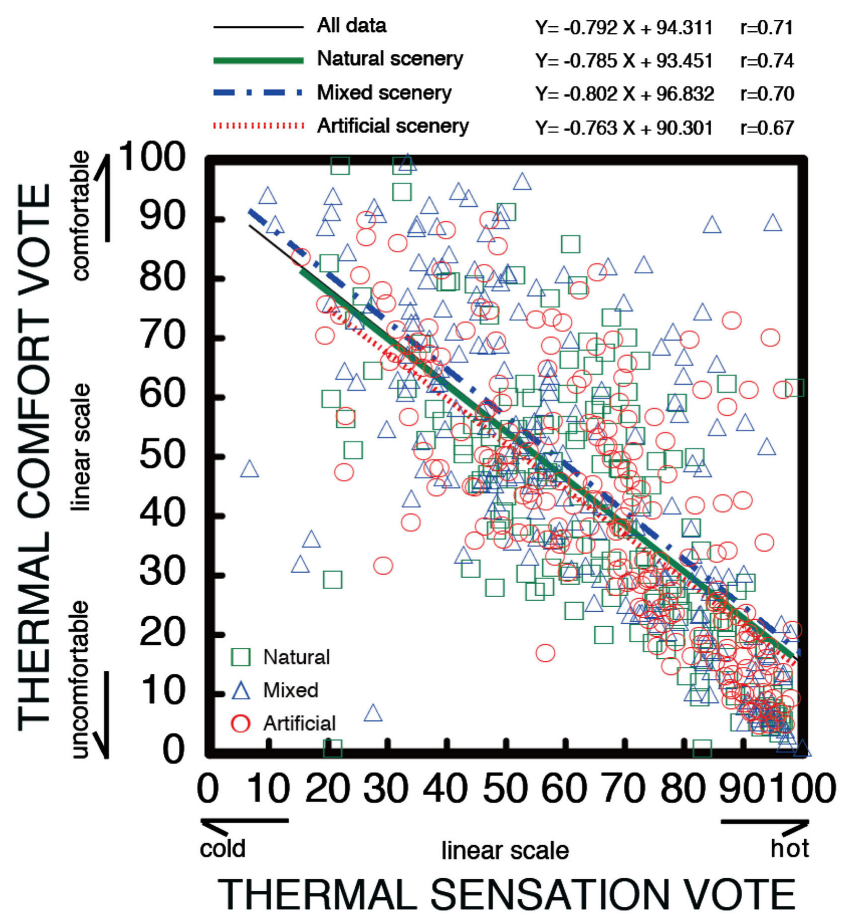

Figure 6. Relationship between thermal sensation and thermal comfort. 
difference in the homogeneity of the regression lines. As a result of multiple comparison by Tukey-Kramer, mixed scenery and natural scenery, and mixed scenery and artificial scenery were both $\mathrm{p}<0.10(\mathrm{p}=0.03, \mathrm{p}=0.02)$, showing a significant difference. Similar to the relationship between ETFe and thermal comfort, the comfort of mixed scenery is relatively high. Therefore, it can be considered that the influence of green factor was expressed in the thermal comfort.

Focusing on the regression line for all experimental results, the thermal sensation that gives a neither comfortable nor uncomfortable thermal comfort of 50 is the neither hot nor cold thermally neutral 56.0. When a comfortable ETFe is obtained from the relationship between ETFe and thermal sensation according to this condition as shown in Figure 2, ETFe is obtained as $35.2^{\circ} \mathrm{C}$. As stated in Kurazumi et al. [11], the sense of expectation for the degree of comfort in outdoor spaces is low to begin with and they are not judged to be comfortable thermal environments, so it is conceivable that even thermal environments with a high ETFe or in which mean skin temperature becomes high were permitted.

Höppe [61], Nikolopoulou and Steemers [5], Spagnolo and de Dear [62], Nakano and Tanabe [63], Ahmed [64], Oliveira and Andrade [14], Lin and Matzarakis [65], Cheng et al. [66] and Kurazumi et al. [10] consider the allowable range of comfort in an outdoor space to be wider than that in an indoor space. Also, Kurazumi et al. [10] shows an ETFe of $31.6^{\circ} \mathrm{C}-38.5^{\circ} \mathrm{C}$ to be a comfortable thermal environment range for outdoor spaces in urban areas.

Kurazumi et al. [53] shows that tolerance limit is higher in an outdoor space than in an indoor space. Compared with the urban environment, the difference in the perceptual environment, whereby it is subconsciously assumed to be a comfortable thermal environment, had an effect in the rural and suburban regional environment, resulting in an ETFe lower than the upper limit of comfort in a summer urban environment of Kurazumi et al. [10].

\section{Conclusions}

Focusing on the rural and suburban regions where paddy fields remain, subject experiments were conducted to clarify the effect of thermal environmental factors on the human body in an outdoor space. The relationship between thermal environment evaluation index (ETFe) and the physiological/psychological response of the human body was investigated.

Long-wave length thermal radiation from concrete walls of buildings and stone walls of revetments with high heat capacity becomes strong, and the amount of long-wave length thermal radiation heat gain in the human body increases. Paddy fields, in which the water that has received short-wave length solar radiation does not flow, have a high heat capacity, which works to increase the long-wave length thermal radiation in the time period when the accumulated amount of short-wave length solar radiation increases. A ground surface feature with a high heat capacity may promote the sensation of hot and deteriorate the thermal sensation. 
A landscape of thick vegetation with a high green factor may have a strong feeling of confinement, which can make it somewhat hot and somewhat uncomfortable thermal environment due to the sense of stagnation.

The ETFe that gives a neither hot nor cold, thermally neutral thermal sensation was $30.6^{\circ} \mathrm{C}$. The ETFe that gives neither comfortable nor uncomfortable thermal comfort was $35.5^{\circ} \mathrm{C}$. The mean skin temperature that gives a neither hot nor cold, thermally neutral thermal sensation was $33.0^{\circ} \mathrm{C}$. The mean skin temperature that gives neither comfortable nor uncomfortable thermal comfort was $34.0^{\circ} \mathrm{C}$. The sense of expectation for the degree of comfort in outdoor spaces is low to begin with and they are not judged to be comfortable thermal environments, so it is conceivable that even thermal environments with a high ETFe or in which mean skin temperature becomes high were permitted.

The thermal sensation that gives neither comfortable nor uncomfortable thermal comfort was a neither hot nor cold thermally neutral 56.0. When a comfortable ETFe is obtained from the relationship between ETFe and thermal sensation according to this condition, ETFe is obtained as $35.2^{\circ} \mathrm{C}$. Compared with the urban environment, it is conceivable that the difference in the perceptual environment, whereby it is subconsciously assumed to be a comfortable thermal environment, had an effect on the rural and suburban regional environment, resulting in an ETFe lower than the upper limit of comfort in a summer urban environment.

\section{Acknowledgements}

We would like to express our sincerest gratitude to the study subjects who participated in the present study.

\section{Conflicts of Interest}

The authors declare no conflicts of interest regarding the publication of this paper.

\section{References}

[1] Humphreys, M. (1976) Field Studies of Thermal Comfort Compared and Applied. Building Services Engineer, 44, 5-27.

[2] Brager, G.S. and deDear, R.J. (1998) Thermal Adaptation in the Build Environment: A Literature Review. Energy and Buildings, 27, 83-96. https://doi.org/10.1016/S0378-7788(97)00053-4

[3] Nikolopoulou, M., Baker, N. and Steemers, K. (2001) Thermal Comfort in Outdoor Urban Spaces, Understanding the Human Parameter. Solar Energy, 70, 227-235. https://doi.org/10.1016/S0038-092X(00)00093-1

[4] de Dear, R.J. and Brager, G.S. (2002) Thermal Comfort in Naturally Ventilated Buildings, Revisions to ASHRAE Standard 55. Energy and Buildings, 34, 549-561. https://doi.org/10.1016/S0378-7788(02)00005-1

[5] Nikolopoulou, M. and Steemers, K. (2003) Thermal Comfort and Psychological Adaptation as a Guide for Designing Urban Spaces. Energy and Buildings, 35, 95-101. https://doi.org/10.1016/S0378-7788(02)00084-1 
[6] Knez, I. and Thorsson, S. (2006) Influence of Culture and Environmental Attitude on Thermal, Emotional and Perceptual Evaluations of a Square. International Journal of Biometeorology, 50, 258-268. https://doi.org/10.1007/s00484-006-0024-0

[7] Nikolopoulou, M. and Lykoudis, S. (2006) Thermal Comfort in Outdoor Urban Spaces: Analysis across Different European Countries. Building and Environment, 41, 1455-1470. https://doi.org/10.1016/j.buildenv.2005.05.031

[8] Kántor, N. and Unger, J. (2011) Benefits and Opportunities of Adopting GIS in Thermal Comfort Studies in Resting Places: An Urban Park as an Example. Landscape and Urban Planning, 98, 36-46.

https://doi.org/10.1016/j.landurbplan.2010.07.008

[9] Kurazumi, Y., Tsuchikawa, T., Matsubara, N., Kondo, E. and Horikoshi, T. (2011) Evaluation of Enhanced Conduction-Corrected Modified Effective Temperature ETFe as the Outdoor Thermal Environment Evaluation Index. Energy and Buildings, 43, 2925-2937. https://doi.org/10.1016/j.enbuild.2011.07.019

[10] Kurazumi, Y., Tsuchikawa, T., Kondo, E., Ishii, J., Fukagawa, K., Yamato, Y., Tobita, K., Ando, Y., Matsubara, N. and Horikoshi, T. (2012) Thermal Comfort Zone in Outdoor Environment. Journal of Human and Living Environment, 19, 115-127.

[11] Kurazumi, Y., Ishii, J., Kondo, E., Fukagawa, K., Bolashikov, Z.D., Sakoi, T., Tsuchikawa, T., Matsubara, N. and Horikoshi, T. (2014) The Influence of Outdoor Thermal Environment on Young Japanese Female. International Journal of Biometeorologyogy, 58, 963-974. https://doi.org/10.1007/s00484-013-0681-8

[12] Kurazumi, Y., Fukagawa, K., Yamato, Y., Tobita, K., Kondo, E., Tsuchikawa, T., Horikoshi, T. and Matsubara, N. (2011) Enhanced Conduction-Corrected Modified Effective Temperature as the Outdoor Thermal Environment Evaluation Index upon the Human Body. Building and Environment, 46, 12-21.

https://doi.org/10.1016/j.buildenv.2010.06.012

[13] Givoni, B., Noguchi, M., Saaroni, H., Pochter, O., Yaacov, Y., Feller, N. and Becker, S. (2003) Outdoor Comfort Research Issues. Energy and Buildings, 35, 77-86. https://doi.org/10.1016/S0378-7788(02)00082-8

[14] Oliveira, S. and Andrade, H. (2007) An Initial Assessment of the Bioclimatic Comfort in an Outdoor Public Space in Lisbon. International Journal of Biometeorologyogy, 52, 69-84. https://doi.org/10.1007/s00484-007-0100-0

[15] Eliasson, I., Knez, I., Westerberg, U., Thorsson, S. and Lindberg, F. (2007) Climate and Behaviour in a Nordic City. Landscape and Urban Planning, 82, 72-84. https://doi.org/10.1016/j.landurbplan.2007.01.020

[16] Ishii, J., Horikoshi, T., Kurazumi, Y., Nagano, K. and Fukagawa, K. (2008) A Field Survey of Thermal Comfort in Outdoor Space. 18th International Congress of Biometeorology, Tokyo, 22-26 September 2008, 1-4.

[17] Kurazumi, Y., Kondo, E., Ishii, J., Sakoi, T., Fukagawa, K., Bolashikov, Z.D., Tsuchikawa, T., Matsubara, N. and Horikoshi, T. (2013) Effect of the Environmental Stimuli upon the Human Body in Winter Outdoor Thermal Environment. Journal of Environmental and Public Health, 2013, Article ID: 418742. https://doi.org/10.1155/2013/418742

[18] Kurazumi, Y., Ishii, J., Fukagawa, K. and Aruninta, A. (2015) The Influence of Tropical Urban Climate upon the Human Body. International Joint-Conference of SENVAR-iNTA-AVAN, Johor, 24-26 November 2015, 105-114.

[19] Kurazumi, Y., Ishii, J., Fukagawa, K., Kondo, E. and Aruninta, A. (2016) Ethnic Differences in Thermal Responses between Thai and Japanese Females in Tropical Urban Climate. American Journal of Climate Change, 5, 52-68. 
https://doi.org/10.4236/ajcc.2016.51007

[20] Kurazumi, Y., Ishii, J., Fukagawa, K., Kondo, E., Nyilas, A. and Aruninta, A. (2017) Seasonal Differences of Psychological and Physiological Responses in Tropical Urban Climate. Health, 9, 896-920. https://doi.org/10.4236/health.2017.96064

[21] Murakawa, S., Sekine, T., Narita, K. and Nishina, D. (1988) Study on the Effect of River on Thermal Environment in Urban Area. Journal of Architecture, Planning and Environmental Engineering, 393, 25-34. https://doi.org/10.3130/aijax.393.0_25

[22] Murakawa, S., Sekine, T., Narita, K., Nishina, D. and Senda, K. (1988) Study on the Effect of River on Thermal Environment in Urban Area (Part 2). Journal of Architecture, Planning and Environmental Engineering, 415, 9-19.

[23] Gao, W., Miura, S. and Ojima, T. (1994) Site Survey on Formation of Thermal Cool Island Due to Park and Inner River in Koto-Ku, Tokyo, Thermal Effects of the Open Space with Green Area on the Urban Environment Part II. Journal of Architecture, Planning and Environmental Engineering, 456, 75-83. https://doi.org/10.3130/aija.59.75_1

[24] Hashimto, T. and Horikoshi, T. (2003) The Effects of Shonai and Shinkawa Rivers Running around the Outskirts of Nagoya as "Wind Trail" of the Sea Breeze on the Urban Thermal Environment. Journal of Environmental Engineering, 571, 55-62. https://doi.org/10.3130/aije.68.55_2

[25] Kiyota, T., Taniguchi, A., Kiyota, N. and Nakamura, Y. (2006) The Study on Countermeasures against the Heat Island Phenomenon in the Urban Area: Part 1 The Characteristics of Air Temperature in the Urban Area of Hiroshima among Calm, Sea Breeze and Land Breeze. Journal of Environmental Engineering, 602, 69-75. https://doi.org/10.3130/aije.71.69_1

[26] Sasaki, K., Junimura, Y., Mochida, A., Watanabe, H. and Yoshino, H. (2007) Field Measurements of Regional Climate in a Provincial Coastal City along the Pacific in Tohoku Region in Summer, Influence of Wind Condition, Such as Yamase, and Green Coverage Ratio on Air Temperature. Journal of Environmental Engineering, 613, 99-85. https://doi.org/10.3130/aije.72.79_1

[27] Ishii, A., Katayama, T., Nishida, M., Hayashi, T., Shiozuki, Y., Tutsumi, J., Kitayama, H, Takayama, K., Murooka, H. and Ooguro, M. (1989) Thermal Environment in the Urban Area around the Park with a Large Pond, Comparison of When Water Filing and When Water Pumped out for Cleaning the Bed. Summaries of Technical Papers of Annual Meeting Architectural Institute of Japan, D Environmental Engineering, 1087-1088.

[28] Fukagawa, K., Shimazawa, T., Muranaka, S., Koshikawa, Y. and Ando, M. (2006) A Study of the Differences on the Formation of Temperature among Urban Areas, Rural Areas, and around Irrigation Ponds in a Developing City. Journal of Environmental Engineering, 605, 95-102. https://doi.org/10.3130/aije.71.95_2

[29] Fukagawa, K., Murakawa, S., Nishida, D. and Shimazawa, T. (2008) Formation of the Temperature in Summer beside Agricultural Irrigation Ponds Located in Urban Area. Journal of Environmental Engineering, 626, 503-510. https://doi.org/10.3130/aije.73.503

[30] Nishida, K., Mitsuyasu, M., Yoshida, S. and Shirozawa, S. (2017) Relationship between Water Depth and Water and Soil Temperature in a Paddy Field during Rice Ripening Period. Irrigation, Drainage and Rural Engineering Journal, 305, 253-263.

[31] World Medical Association (2018) WMA Declaration of Helsinki-Ethical Principles for Medical Research Involving Human Subjects. https://www.wma.net/policies-post/wma-declaration-of-helsinki-ethical-principles- 
for-medical-research-involving-human-subjects/

[32] Kurazumi, Y., Horikoshi, T., Tsuchikawa, T. and Matsubara, N. (1994) The Body Surface Area of Japanese. Japanese Journal of Biometeorology, 31, 5-29.

[33] Kurazumi, Y., Tsuchikawa, T., Yamato, Y., Kakutani, K., Matsubara, N. and Horikoshi, T. (2003) The Posture and Effective Thermal Convection Area Factor of the Human Body. Japanese Journal of Biometeorology, 40, 3-13.

[34] Hanada, K., Mihira, K. and Ohhata, K. (1981) Studies on the Thermal Resistance of Women's Underweares. Journal of the Japan Research Association for Textile End-Use, 22, 430-437.

[35] Hanada, K., Mihira, K. and Sato, Y. (1983) Studies on the Thermal Resistance of Men's Underweares. Journal of the Japan Research Association for Textile End-Use, 24, 363-369.

[36] Horikoshi, T. and Kobayashi, Y. (1985) Corrected Humid Operative Temperature as an Index of Combined Influences of Thermal Conditions upon the Human Body. Journal of Architecture, Planning and Environmental Engineering, 355, 12-19. https://doi.org/10.3130/aijax.355.0_12

[37] Horikoshi, T., Kobayashi, Y. and Tsuchikawa, T. (1991) Indices of Combined and Independent Effect of Thermal Environmental Variable upon the Human Body. ASHRAE Transactions, 97, 228-238.

[38] Kurazumi, Y., Tsuchikawa, T., Torii, T., Kakutani, K., Matsubara, N. and Horikoshi, T. (2004) Weighting Coefficients for Calculating Mean Skin Temperature When Considering Convective Heat Transfer Areas. Journal of the Human-Environmental System, 7, 19-28. https://doi.org/10.1618/jhes.7.19

[39] Kurazumi, Y., Matsubara, N., Furukawa, N., Fujiwara, M., Ue, A., Ueki, Y., Nagai, H. and Yamamoto, S. (1998) Japanese Weighting Coefficients for Calculating Mean Skin Temperature in Relation to Posture. Japanese Journal of Biometeorology, 35, 121-132.

[40] Kurazumi, Y., Tsuchikawa, T., Kakutani, K., Torii, T., Matsubara, N. and Horikoshi, T. (2003) Evaluation of the Calculation Formula for the Body Surface Area of the Human Body. Japanese Journal of Biometeorology, 39, 101-106.

[41] Kurazumi, Y., Tsuchikawa, T., Matsubara, N. and Horikoshi, T. (2008) Effect of Posture on the Heat Transfer Areas of the Human Body. Building and Environment, 43, 1555-1565. https://doi.org/10.1016/j.buildenv.2007.09.001

[42] Miyamoto, S., Horikoshi, T. and Hirokawa, Y. (1998) Projected Area Factors of the Human Body at Standing Posture under Different Clothing Conditions. Journal of Architecture, Planning and Environmental Engineering, 513, 47-52. https://doi.org/10.3130/aija.63.47_4

[43] Kuwabara, K., Mochida, T., Kondo, M. and Matsunaga, K. (2003) Measurement of Man's Convective Heat Transfer Coefficient by Using a Thermal Manikin in the Middle Wind Velocity Region. Journal of Human and Living Environment, 8, 27-32.

[44] Hendler, E., Crosbie, R. and Hardy, J.D. (1958) Measurement of Heating of the Skin during Exposure to Infrared Radiation. Journal of Applied Physiology, 12, 177-185. https://doi.org/10.1152/jappl.1958.12.2.177

[45] VDI (2008) VDI 3787-2, Environmental Meteorology-Methods for the Human Biometeorological Evaluation of Climate and Air Quality for Urban and Regional Planning at Regional Level-Part 1: Climate. Beuth, Berlin.

[46] Watanabe, S., Horikoshi, T. and Tomita, A. (2010) Measurement of Solar Radiation Absorptance of Clothed Human Body in Outdoor. Japanese Journal of Biomete- 
orology, 47, 165-173.

[47] Elam, R., Goodwin, D.W. and Lloyd Williams, K. (1963) Optical Properties of the Human Epidermis. Nature, 198, 1001-1002. https://doi.org/10.1038/1981001a0

[48] Kurazumi, Y., Sakoi, T., Tsuchikawa, T., Fukagawa, K., Bolashikov, Z.D. and Horikoshi, T. (2014) Behavioral Thermoregulation Model for Evaluation of Outdoor Thermal Environment. Journal of Ergonomics, 4, 1-14. https://doi.org/10.4172/2165-7556.1000125

[49] Kurazumi, Y., Nakamura, R. and Matsubara, N. (2000) Effect of Different Postures on the Resting Metabolic Rate of Young Japanese at Operative Temperature of 28 ${ }^{\circ} \mathrm{C}$. Japanese Journal of Biometeorology, 37, 27-37.

[50] Horikoshi, T., Kurazumi, Y., Hirayama, K., Tsuchikawa, T. and Kobayashi, Y. (1989) Indication of the Effect of Asymmetric Thermal Radiation of the Human Physiological and Psychological Responses. The Second World Congress on Heating, Ventilating, Refrigerating and Air Conditioning, Sarajevo, 27 August-1 September 1989, 188-193.

[51] Kurazumi, Y., Horikoshi, T., Hirayama, K., Tsuchikawa, T. and Kobayashi, Y. (1993) The Influence of Asymmetric and Uneven Thermal Radiation Environments upon the Human Body, in the Case of Constant Operative Temperature. Journal of Architecture, Planning and Environmental Engineering, 447, 17-26. https://doi.org/10.3130/aijax.447.0_17

[52] Kurazumi, Y., Saito, K. and Horikoshi, T. (1994) The Influence of Asymmetric Thermal Radiation Environments upon the Human Body, in the Case of Constant Operative Temperature and Right and Left, Back and Forth Asymmetry. Japanese Journal of Biometeorology, 31, 75-84.

[53] Kurazumi, Y., Matsubara, N., Tsuchikawa, T., Kondo, E., Ishii, J., Fukagawa, K., Ando, Y., Yamato, Y., Tobita, K. and Horikoshi, T. (2011) Psychological Effects of the Environmental Stimuli on Thermal Sense in Outdoor Spaces. Japanese Journal of Biometeorology, 48, 129-144.

[54] Kurazumi, Y., Fukagawa, K., Kondo, E., Yamato, Y. and Tobita, K. (2015) The Influence of Solar Radiation upon the Human Body. The 15th Science Council of Asia Conference and International Symposium, Siem Reap City, 15-16 May 2015, 154-158.

[55] Fukagawa, K., Kurazumi, Y., Yamato, Y., Tobita, K., Hase, H., Han, S., Oishi, H. and Cao, Z. (2010) The Effect of Visual Stimulus on Thermal Comfort, Analysis of the Visual Factor by Experiment. The 7 th International Cost Engineering Council World Congress \& The 14th Pacific Association of Quantity Surveyors Congress, Singapore, 23-27 July 2010, 1-10.

[56] Kurazumi, Y., Fukagawa, K., Kondo, E. and Sakoi, T. (2014) Effects of Visual Stimuli upon Thermal Sense under Air Conditioning in Summer. Journal of Ergonomics, 4, 1-7.

[57] Kurazumi, Y., Kondo, E., Fukagawa, K., Hashimoto, R., Nyilas, A., Sakoi, T. and Tsuchikawa, T. (2017) The Influence of Foliage Plants on Psychological and Physiological Responses. Health, 9, 601-621. https://doi.org/10.4236/health.2017.94043

[58] Kurazumi, Y., Hashimoto, R., Nyilas, A., Yamashita, K., Fukagawa, K., Kondo, E., Yamato, Y., Tobita, K. and Tsuchikawa, T. (2018) Effect of Visual Stimuli of Indoor Floor Plants upon the Human Responses. Health, 10, 928-948. https://doi.org/10.4236/health.2018.107069

[59] Kurazumi, Y., Fukagawa, K., Sakoi, T., Aruninta, A. and Yamashita, K. (2018) The Non-Uniform and Asymmetric Thermal Radiation upon the Human Physiological 
Responses in Outdoor Environment. International Journal of Environmental Research and Public Health, 10, 1321-1341.

https://doi.org/10.20944/preprints201807.0274.v1

[60] Tsuchikawa, T., Horikoshi, T., Kurazumi, Y., Hirayama, K., Kondo, E. and Kobayashi, Y. (1991) Effects of Thermal Radiation on Human Body in Standing Posture. Journal of Architecture, Planning and Environmental Engineering, 422, 27-35. https://doi.org/10.3130/aijax.422.0_27

[61] Höppe, P. (2002) Different Aspects of Assessing Indoor and Outdoor Thermal Comfort. Energy and Buildings, 34, 661-665.

https://doi.org/10.1016/S0378-7788(02)00017-8

[62] Spagnolo, J. and de Dear, R.J. (2003) A Field Study of Thermal Comfort in Outdoor and Semi-Outdoor Environments in Subtropical Sydney Australia. Building and Environment, 38, 721-738. https://doi.org/10.1016/S0360-1323(02)00209-3

[63] Nakano, J. and Tanabe, S. (2004) Thermal Comfort and Adaptation in Semi-Outdoor Environments. ASHRAE Transactions, 110, 543-553.

[64] Ahmed, K.S. (2003) Comfort in Urban Spaces: Defining the Boundaries of Outdoor Thermal Comfort for the Tropical Urban Environments. Energy and Buildings, 35, 103-110. https://doi.org/10.1016/S0378-7788(02)00085-3

[65] Lin, T.P. and Matzarakis, A. (2008) Tourism Climate and Thermal Comfort in Sun Moon Lake, Taiwan. International Journal of Biometeorologyogy, 52, 281-290. https://doi.org/10.1007/s00484-007-0122-7

[66] Cheng, M., Lo, J. and Chen, S. (2011) Investigation of the Effect of Climatic Adaptation on Users' Thermal Comfort Requirement in Outdoor Space. International Journal of the Physical Sciences, 6, 6042-6052. 